\title{
Stochastic analysis of rainfall effect on earthquake induced shallow landslide of Tandikat, West Sumatra, Indonesia
}

\author{
Fikri Faris ${ }^{*}$ and Fawu Wang
}

\begin{abstract}
Background: On September 30, 2009, extensive landslides occurred in Tandikat, Padang Pariaman Regency, West Sumatra Province, Indonesia, burying hundreds of people, and flattening some villages after a Mw 7.6 earthquake hit West Sumatra coast. The landslides occurred during rainfall, and originated on mountains mantled with loose pumice. The probability of concurrent earthquake and rainfall event in this area requires landslide hazard evaluation by considering the effect of the unfortunate combination of rainfalls and earthquakes. To evaluate the landslide hazard level, the term of specific volume ratio (RSV) was used as the ratio of displaced volume to the maximum volume per unit width that could collapse from the slope. Combined analysis of groundwater model and slope stability was utilized to determine the landslide hazard level. Stochastic analysis using Monte-Carlo method was implemented to deal with uncertainties in determining slope stability.

Results: The stochastic analysis of the Tandikat landslide confirms that smaller earthquakes could possibly trigger catastrophic landslides during rainfall. Smaller peak ground acceleration of approximately $0.15 \mathrm{~g}$ could result in a more than $60 \%$ chance of Rsv $>0.75$, while the analysis of dry condition yields a $30 \%$ chance of catastrophic level of landslide hazard. This suggests that rainfall condition increases the probability of catastrophic landslide.

Conclusion: The stochastic analysis of the Tandikat landslide confirms that smaller earthquakes could possibly trigger catastrophic landslides during rainfall. The results also suggest that peak ground acceleration of approximately $0.3 \mathrm{~g}$ is considered as the critical magnitude of ground acceleration that could result in a nearly $100 \%$ probability of catastrophic level of landslide hazard in the area.
\end{abstract}

Keywords: Tandikat landslide; Earthquake; Rainfall; Shallow landslide; Stochastic analysis

\section{Background}

On September 30, 2009, an earthquake with moment magnitude of 7.6 hit West Sumatra coast in Indonesia, triggering many landslides on mountainous regions. The most extensive landslides occurred in Tandikat, Padang Pariaman Regency, burying hundreds of people, and flattening some villages (Figure 1). Extensive rainfall is considered to have saturated a loose pumice ash layer on the mountains before the earthquake. In this particular area, the probability of concurrent earthquake and rainfall events is high, since the area has a tropical rainforest climate, and is also situated on a seismically active plate margin. Consequently, it is essential to evaluate the landslide hazard of particular event by

\footnotetext{
* Correspondence: fikri.faris.ugm@gmail.com

Department of Geoscience, Shimane University, Matsue 690-8504, Japan
}

considering the effect of the unfortunate combination of independent events such as rainfalls and earthquakes.

\section{Effect of rainfall on earthquake- induced landslides}

Researches focusing on the effect of rainfall on earthquake induced landslides are scarcely found in literatures. Sassa (2005) reported landslide disasters triggered by the 2004 Mid-Niigata Prefecture earthquake in Japan. The earthquake occurred 3 days after heavy rainfall of Typhoon no. 23. The influence of rainfall on soil moisture prior to the earthquake was evaluated by Japan Meteorological Agency. They used hydrological model to obtain Soil Water Index (SWI) representing amount of water stored under the ground surface. The landslides then were compared with those induced by the 1995 Hyogoken-Nambu earthquake during dry season. The 2004 Mid-Niigata earthquake 


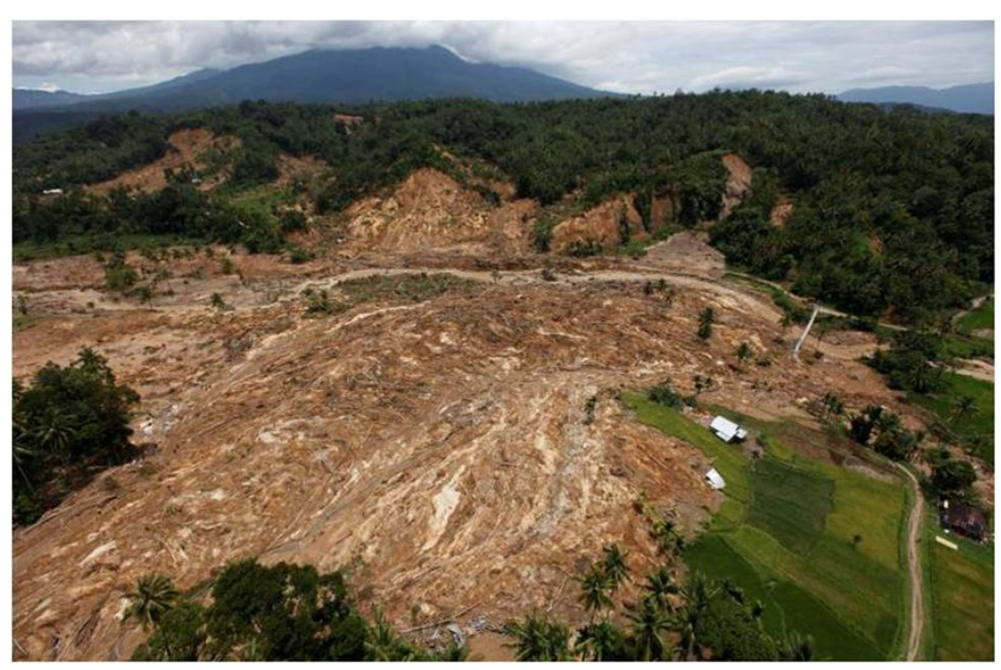

Figure 1 An aerial view of an area affected by the landslide in Tandikat, Padang Pariaman, West Sumatra, Indonesia (Photo courtesy of IFRC, 2009).

triggered 362 landslides with a width more than $50 \mathrm{~m}$ and 12 large-scale landslides with volumes of more than 1 million cubic meters, while the only significant landslide triggered by the Hyogoken-Nambu earthquake was the $125 \mathrm{~m}$ wide Nikawa landslide with long run out distance. This large difference was probably caused by the heavy rainfall prior to the Mid-Niigata earthquake. Based on this fact, Sassa (2005) underscored that the combined effect of rainfall and earthquakes is necessary to evaluate landslide risk.

The study conducted by Chang et al. (2007) implemented the effect of rainfall on earthquake-induced landslide. They used a logistic regression to develop both earthquake- and typhoon-induced landslide models by considering a typhoon prior to the earthquake.

The initiation mechanism of earthquake- induced landslide after rainfall was studied by Uzuoka et al. (2005). They performed site investigation, laboratory test and numerical simulation of Nishisaruta landslide triggered by July 26, 2003 Miyagi earthquake. The result confirmed that high rainfall occurred 3 days before the earthquake was an important factor of the landslide. The rainfall was supposed to have saturated the landslide mass before the earthquake and the main shock triggered the liquefaction of the sand fill in the slope, dramatically decreasing its stability.

Abovementioned researches confirm the necessity of considering the effect of rainfall prior to an earthquake. However, as far as we know, study about the effect of rainfall during earthquake is scarce in the literature due to the exceptionality of the combined event of rainfall and earthquake. Faris and Wang (2014) have studied the mechanisms of the landslide that occurred in Tandikat, West Sumatra, Indonesia. They developed pore pressure model of Tandikat pumice sand based on cyclic triaxial tests and conducted deterministic numerical simulation to evaluate the landslide mechanism of the landslide. They suggested that both the effect of acceleration and the pore pressure build-up were involved. However, probabilistic approaches of the particular event have not yet been examined. Probabilistic analysis is needed to be considered to incorporate the heterogeneity of the slope material. This paper aims to evaluate the landslide hazard of particular event using probabilistic approach considering the effect of the proceeding rainfalls and earthquakes acceleration.

\section{Stochastic slope stability analysis}

Determining stability in natural slope is a challenging task due to its complex nature and heterogeneity of the slope material. It also involves uncertainties in determining soil parameters and properties due to limited sampling and testing techniques (Griffiths et al. 2002). To deal with uncertainties in determining slope stability, a stochastic approach involving random variables was used.

The probabilistic analyses were widely used in geotechnical field to deal with significant uncertainties with regards to slope stability (Chowdhury and Xu 1994). Many researches implemented probabilistic approach by using a Monte-Carlo procedure to consider uncertainty in assessing earthquake-induced landslide, e.g. Wang et al. (2008), Refice and Capolongo (2002), Shou and Wang (2003). Likewise, this paper used a Monte-Carlo simulation to deal with the uncertainty of soil parameters in obtaining probability of a landslide occurrence.

\section{Description of study area \\ Geological setting}

The Tandikat landslides occurred in Nagari Tandikat, Padang Pariaman Regency, West Sumatra Province, near the western coast of Sumatra, Indonesia (Figure 2). This area 


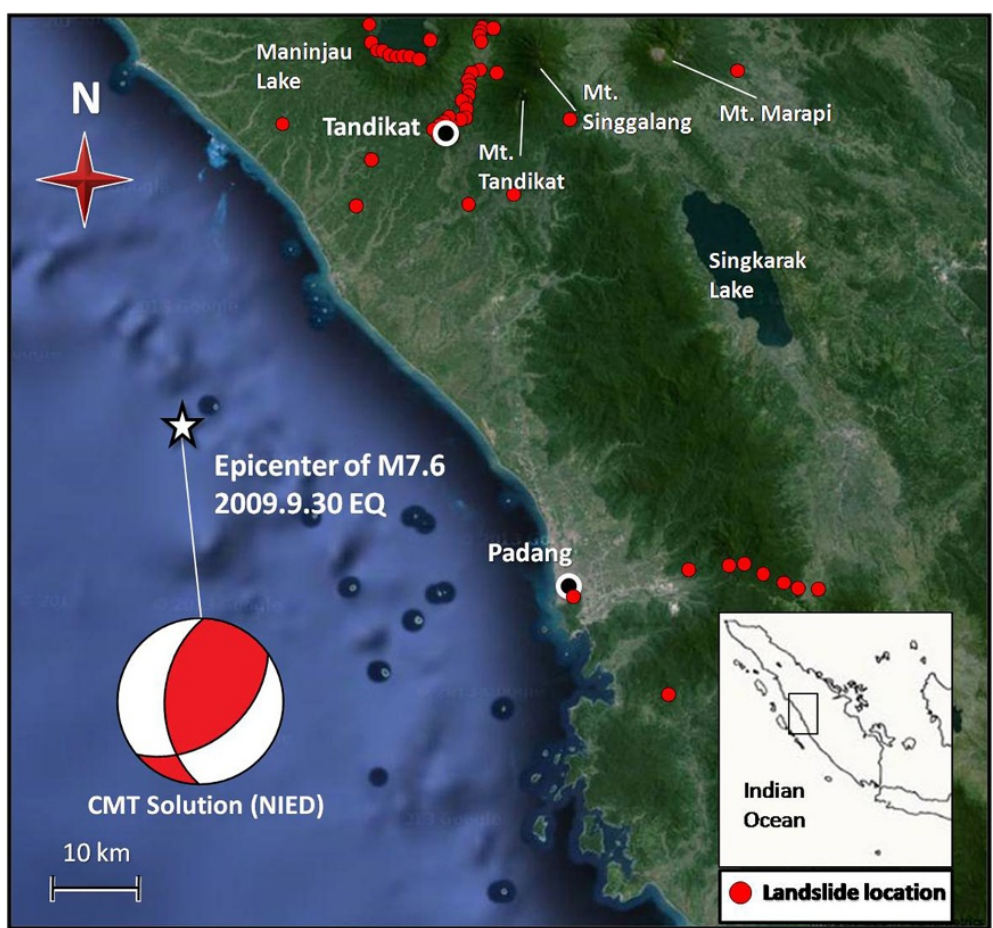

Figure 2 Location of the earthquake epicenter and landslide area (modified from Google Map, 2014).

experiences frequent high intensity earthquakes, due to the oblique movement of the Indo-Australia and Euro-Asian plates that form the Sumatran Fault System (Aydan 2009).

The landslides are located in a mountainous area and are extensively distributed on steep slopes inclined at 30 to 50 degrees. The slopes are mainly mantled by loose volcanic deposits that were derived from the nearby volcanic mountains. This topographical condition is considered to be an important contributory factor for landslides in Tandikat.

According to the Padang geological map (Petersen et al. 2007) in Figure 3, landslide distribution was concentrated on Quaternary volcanic bedrock, denoted as Qvf (Quaternary volcanic rocks along flank of volcanoes). The surface deposits consist of silts, sands, and gravels, with remnants of pumice-tuff. Particularly in this area, impermeable clay strata are overlain by a porous pumice sand layer. From observations of landslide scarps and outcrops, the pumice sand deposits are clearly distinguishable from the clay strata (Figure 4a). Measurements show that the thickness of the pumice sand layers is generally about 2 to 3 meters. Low permeability of the clay stratum was confirmed from water ponding, which was observed on the exposed sliding surface of the clay layer (Figure 4b).

Rainfall infiltration analysis of particular event has been conducted by Faris and Wang (2014) by utilizing GreenAmpt method. The result shows that the depth of the wet front $\left(z_{\mathrm{w}}\right)$ had already surpassed the three-metre depth where the impermeable sandy clay is located (Figure 5). It suggests that water percolated into the pumice sand during rainfall and generated a temporary perched groundwater table above the impermeable sandy clay layer, which consequently created fully saturated conditions in the lower part of the pumice sand. High permeability and high water content due to antecedent rainfall facilitated the rainfall water percolation into the ground.

\section{Seismicity and meteorology}

Subduction zone along the west coast of Sumatra is seismically an active region that has experienced several high magnitude earthquakes in the last few decades. The most recent large earthquake was the September 30, 2009 Padang earthquake, which had a moment magnitude of $M_{w} 7.6$ (M7.6 2009.09.30). The epicenter was located offshore, WNW of Padang City, and the hypocenter was located at a depth of $80 \mathrm{~km}$, within the oceanic slab of the Indo-Australian plate. This earthquake has been interpreted as an indication of a higher possibility of an imminent mega-earthquake in this region (Aydan 2009).

The M7.6 2009.09.30 earthquake accelerogram was provided by Meteorological and Geophysics Agency of Indonesia (BMKG). Figure 6 shows North-South (N-S) direction and vertical direction of M7.6 2009.09.30 earthquake acceleration. Unfortunately, West-East direction could not be provided due to some technical issues.

One of the most damaged areas due to earthquakeinduced landslide was in Cumanak Village of Nagari 


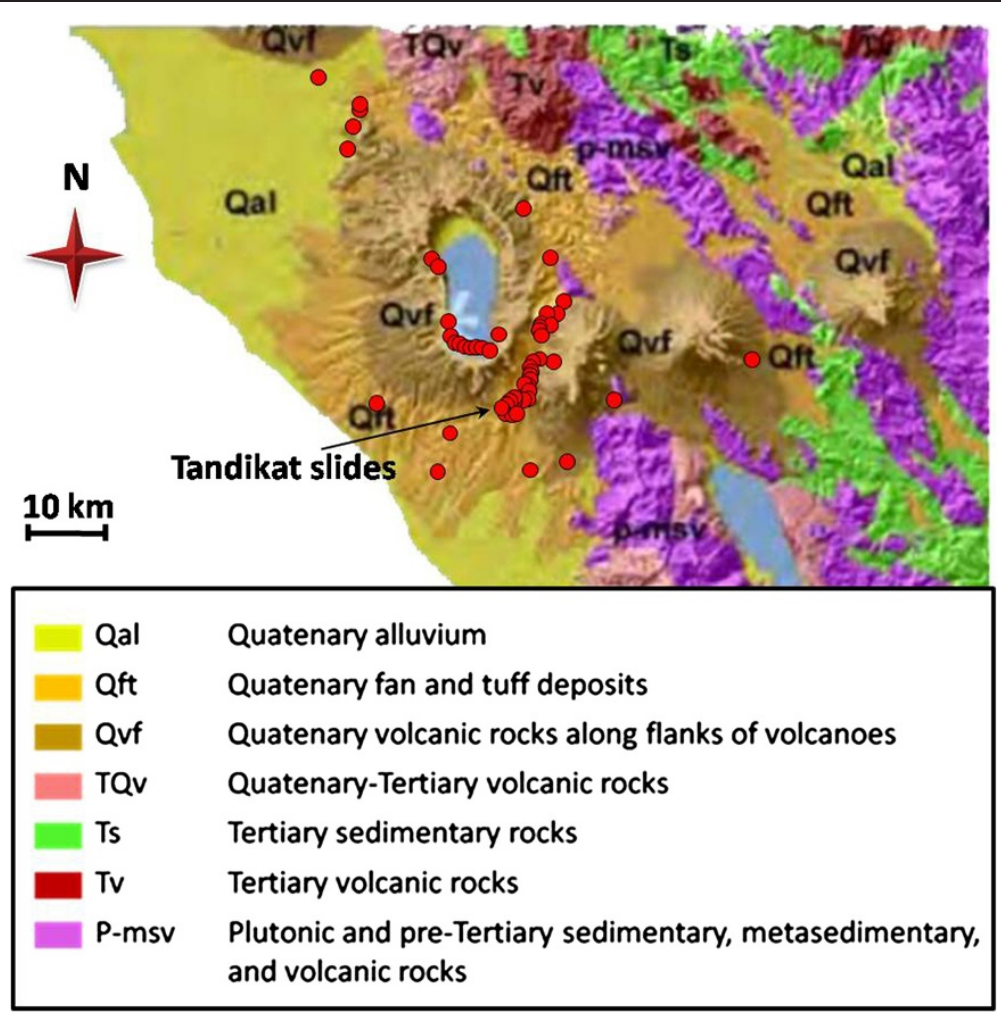

Figure 3 Simplified geology of the earthquake affected area (modified from Petersen et al., 2007).

Tandikat, Patamuan sub-district, Padang Pariaman regency, about $60 \mathrm{~km}$ from the epicenter. Based on rainfall data interpreted from X-band Doppler Radar of the HARIMAU project provided by the Japan Agency for Marine-Earth Science and Technology (JAMSTEC) at Padang Pariaman Regency, rainfall of moderate intensity began at about 12:30, some hours prior to the earthquake shock at 17:16 local time (Figure 6). Antecedent rainfall of $30 \mathrm{~mm} / \mathrm{h}$ was recorded in the previous night. It is suspected that this rainfall played a major role in the triggering of the landslide. The contribution of rainfall to earthquake-induced landslides is of great concern in the volcanic area surrounding the west coast of Sumatra, which has an equatorial weather that usually brings high intensity rainfall, even during dry season periods (Sipayung et al. 2007). Based on the latest meteorological research on west coast of Sumatra, high intensity rainfall is frequently recorded in the late afternoon or evening, and distribution of such rainfall is strongly controlled by the mountainous topography of the area (Wu et al. 2009). The combined effects of seismic activity and meteorological conditions in this area create a high risk of failure of the saturated volcanic deposits during earthquakes. These factors must
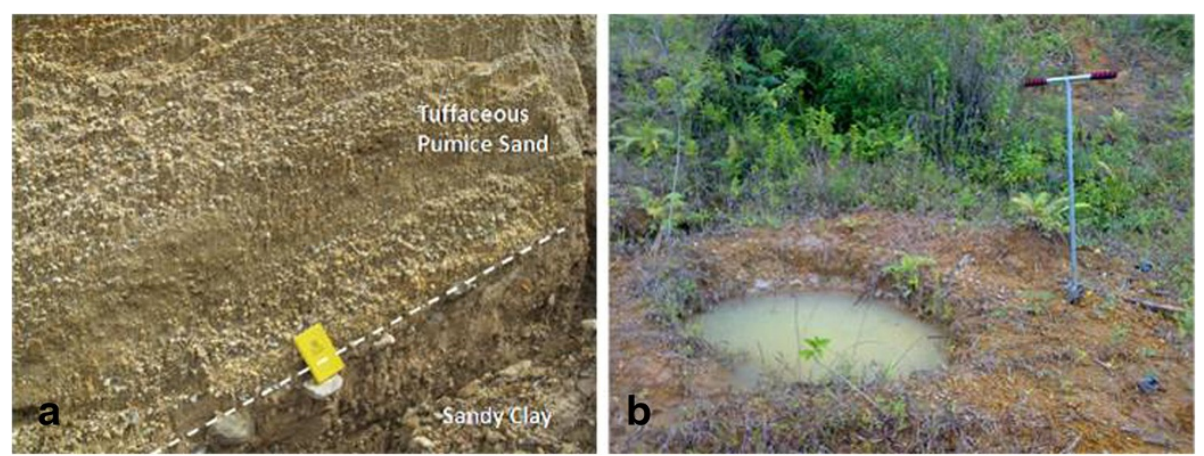

Figure 4 Stratigraphy of Tandikat landslide area; (a) Outcrop showing the distinctive layer of sandy clay overlain by pumice sand; (b) Water ponding on the sandy clay layer, illustrating the low permeability of this layer. 


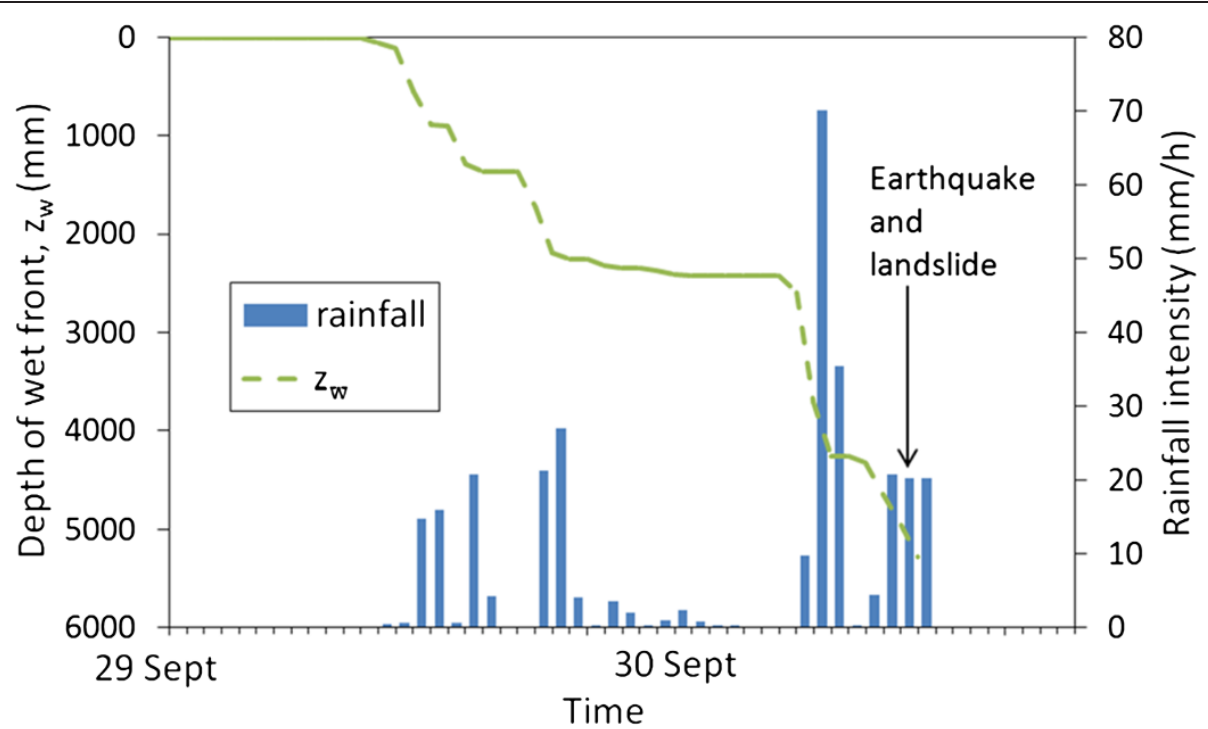

Figure 5 Infiltration analysis result showing depth of the wet front $\left(z_{w}\right)$ development during the 40 hours before the earthquake (Faris and Wang, 2014).

be taken into consideration in geo-hazard assessment and mitigation.

\section{Methods}

\section{Groundwater modelling}

Many researches have been conducted to develop a numerical model to predict groundwater in an unconfined aquifer. Among the many methods, Boussinesq equation is the most oftenly used to estimate groundwater (Bansal and Das 2010). The performance of this method is reliable to predict experimental soil flume test (Steenhuis et al. 1999; Sloan and Moore 1984). This method was generally formulated as a parabolic nonlinear equation.
Thus, finite difference numerical model can be used to utilize the aforesaid equation (Bansal 2013).

The Boussinesq formula as the governing equation of the model is written as Eq. 1 (Bansal 2013).

$$
k\left\{\frac{\partial}{\partial x}\left(h \frac{\partial h}{\partial x}\right) \quad \tan \theta \frac{\partial h}{\partial x}\right\} \cos ^{2} \theta \quad R \quad S \frac{\partial h}{\partial t}
$$

where $h$ is the height of phreatic surface measured above the impermeable sloping bed in the vertical direction, which is the function of distance and time (represented in Figure 7 as $h(x, t)) . k$ and $S$ respectively are the hydraulic conductivity and specific yield of the aquifer. $R$ is
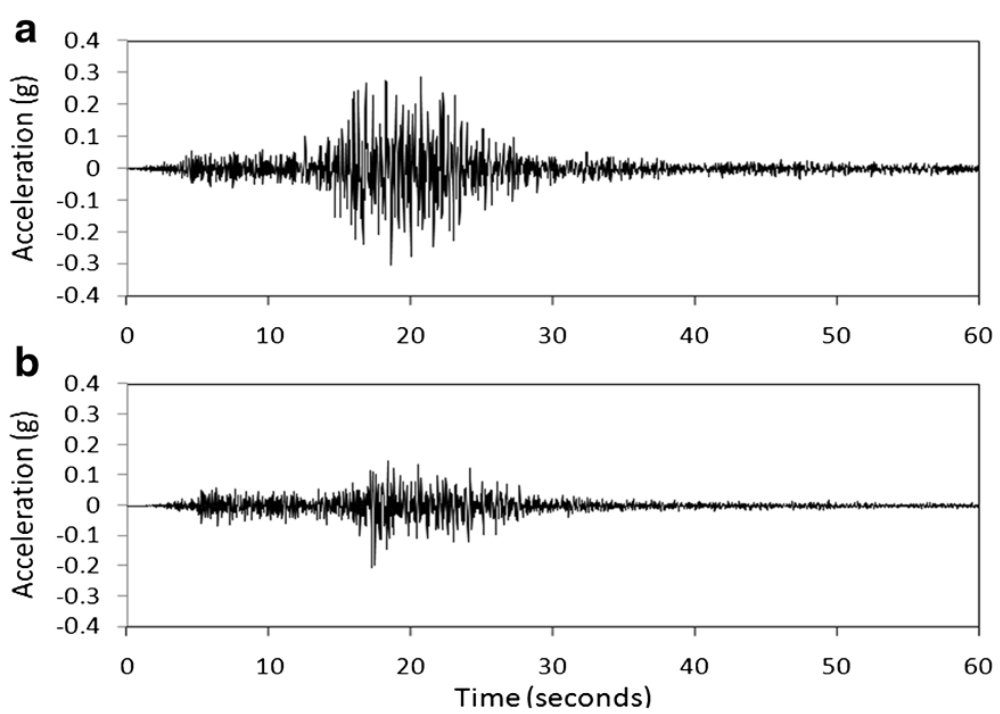

Figure 6 Earthquake accelerogram of M 7.6 2009.09.30 (a) N-S direction (b) Vertical direction (BMKG, 2009). 


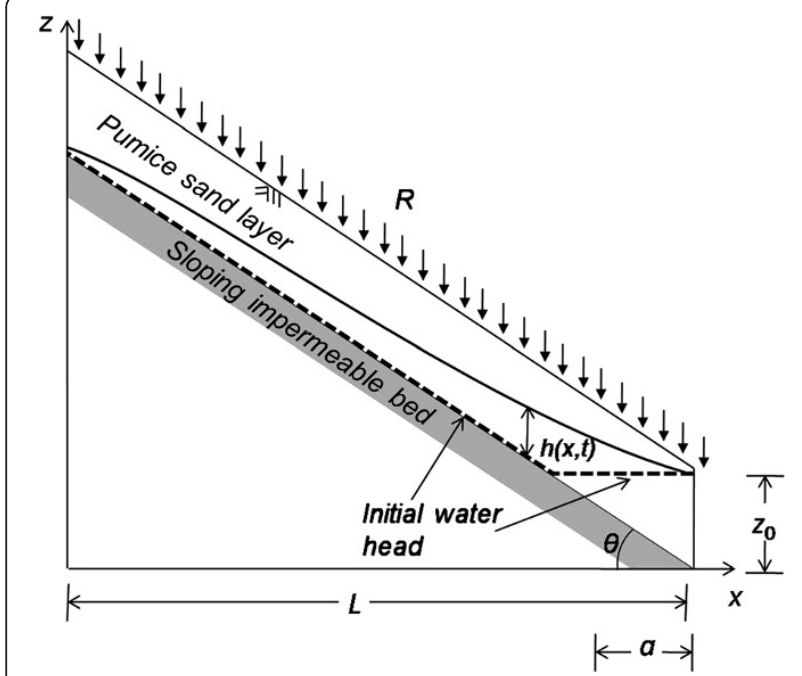

Figure 7 Scheme of groundwater model by rainfall infiltration.

the net rate of recharge of infiltrated rainfall and $\theta$ is the bed slope (Figure 7).

The nonlinear Boussinesq equation can be solved numerically using the Mac Cormack scheme of explicit finite difference method (Bansal 2013). This can be done by modifying the Eq. 1 to Eq. 2:

$$
\frac{\partial h}{\partial t} \quad C_{1} \frac{\partial}{\partial x}\left(h \frac{\partial h}{\partial x}\right) \quad C_{2} \frac{\partial h}{\partial x} \quad \frac{R}{S}
$$

where, $\quad C_{1}=\left(k \cos ^{2} \theta\right) / S$ and $C_{2}=(k \sin 2 \theta) / 2 S$. Mac Cormack scheme is an explicit finite difference with predictor-corrector step. The predictor step is applied by replacing the spatial and temporal derivatives by forwards difference to obtain the predicted value of $h$, indicated as $h$ in Eq. 3.

$$
\begin{aligned}
& \left.h_{n, t} 1 \quad h_{n, t} \quad C_{1} \frac{\Delta t}{\Delta x^{2}}\left[\begin{array}{lllll}
h_{n} & 1, t & \left(h_{n}\right. & 1, t & h_{n, t}
\end{array}\right) \quad h_{n, t}\left(h_{n, t} \quad h_{n} 1, t\right)\right] \\
& C_{2} \frac{\Delta t}{\Delta x}\left(\begin{array}{lll}
h_{n} & 1, t & h_{n, t}
\end{array}\right) \quad \frac{R}{S} \Delta t
\end{aligned}
$$

where subscript $n$ and $t$ are respectively spatial and time identifier. The corrector step is then obtained by replacing the space derivative by rearward difference, while the time derivative is preserved using forward difference approximation, to obtain Eq. 4.

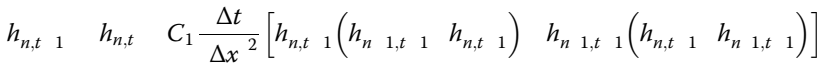

$$
\begin{aligned}
& C_{2} \frac{\Delta t}{\Delta x}\left(\begin{array}{llll}
h_{n, t} & 1 & h_{n} 1, t & 1
\end{array}\right) \quad \frac{R}{S} \Delta t
\end{aligned}
$$

The final value of $h_{n, t+1}$ is simply obtained from arithmetic mean of $h_{n, t \quad 1}$ and $h_{n, t} 1$ from Eqs. 3 and 4, respectively (Eq. 5).

$$
\begin{array}{llll}
h_{n, t} & 1 & \frac{1}{2}
\end{array}\left[\begin{array}{llll}
h_{n, t} & 1 & h_{n, t} & 1
\end{array}\right]
$$

The applied initial condition was used to simulate the water table condition in dry conditions. Thus, the initial and boundary condition are defined by Eqs. 6, 7 and 8 .

$$
\begin{aligned}
& h x, t \quad 0 \quad\left\{\begin{array}{cll}
0 & , x<L & a \\
z_{0} \quad x L \tan \theta & , x>L & a
\end{array}\right. \\
& h 0, t \quad 0 \quad 7 \\
& h L, t \quad z_{0}
\end{aligned}
$$

To accommodate the stochastic analysis, hydraulic conductivity parameter, $k$, was defined as a random variable. The data of hydraulic conductivity was taken from the field test and used as a base to determine statistical parameter for random variable generation.

The specific yield, $S$, has direct relation with effective porosity, $n$ (Eckis 1934 in Robson 1993) where the values of $n$ can be estimated using Kozeny-Carman equation in Eq. 9 (Odong 2007).

$$
k \quad \frac{g}{v} \times 8.3 \times 10^{3}\left[\frac{n^{3}}{1 n^{2}}\right] d_{10}^{2}
$$

where $g$ is the gravitational acceleration (equal to $\left.9.807 \mathrm{~m} / \mathrm{s}^{2}\right), v$ is the kinematic viscosity of water at $20 \mathrm{C}$ (is taken to be $10^{-6} \mathrm{~m}^{2} / \mathrm{s}$ ), $n$ is the effective porosity, and $D_{10}$ is the effective grain size in $\mathrm{mm}$, relative to which $10 \%$ is finer. The specific yield was then estimated from the relation curve provided by Eckis (1934) in Robson (1993). Using a soil category of coarse sand, Eq. 10 is obtained.

$$
S \approx n \quad 0.03
$$

The abovementioned equation is used to define the relation between effective porosity and specific yield in the groundwater model. In the stochastic analysis, specific yield is dependent on the hydraulic conductivity, which was set as a random variable. Therefore, specific yield parameters are automatically counted as random variable.

\section{Slope stability analysis}

Slope stability analysis can be achieved by wide range alternatives from simple single-free-body (i.e. infinite slope assumption) to the more complicated procedures of slices. The aforesaid procedures include such methods as the Janbu s Simplified method, the Simplified Bishop procedure, and Spencer s procedure (Duncan and Wright 2005). All procedures are basically very similar. The differences 
between the methods are the considered equation of statics use in the calculation, and the assumption for the interslice forces (Krahn 2004).

In the standpoint of shallow landslide, many researchers used infinite slope procedure to simplify slope stability calculation. They used some assumptions that may appropriately support the effectiveness of infinite slope procedure, for example: slope failure by homogeneous rainfall infiltration (Iverson 2000; Agus and Liao 2009) and infinite slope with steady seepage parallel to the slope (Romeo 2000). Because the problem deals with varying seepage along the slope that cannot be appropriately analyzed with infinite slope assumption, a more rigorous procedure is considered. This paper uses Janbu s Simplified Method which can satisfy horizontal force equilibrium, yet ignores interslice shear forces. The selection of Janbus Simplified Method is due to the following reasons: 1 ) procedures of slice can be easily dealt with finite difference groundwater model that as well include spatial partition in the analysis; 2) shallow landslides mostly consist of planar type of slip surface, in which the force equilibrium is completely independent of interslice shear force (Krahn 2004); 3) Rapid calculation is necessary to address the probabilistic Monte-Carlo simulation, which will be discussed later. The simulation needs numerous trials to obtain a reasonable result, thus the simplicity of the Janbus Simplified Method ensured a shorter calculation time.

In this paper, the objective to utilize the slope stability analysis is somewhat different from the common purpose. Instead of evaluating the factor of safety, the slope stability analysis is used to calculate the potential amount of sliding mass due to earthquake acceleration in a particular groundwater condition. The amount of sliding mass was termed as specific volume ratio $\left(R_{\mathrm{sv}}\right)$ that is defined as the displaced volume divided by the maximum volume per unit width that could collapse from the slope (Figure 8). The specific volume ratio, $R_{\mathrm{sv}}$ can be formulated by Eq. 11 .

$$
R_{s v} \frac{V_{\mathrm{S}}}{V_{\max }}
$$

where $V_{\mathrm{S}}$ is the specific volume of displaced mass when the factor of safety $\left(F_{\mathrm{SJ}}\right)$ is smaller than one, and $V_{\max }$ is the probable maximum specific volume that could collapse from the slope.

For practical purposes, the slope stability analysis is often simplified by taking into account the horizontal acceleration and neglecting the vertical component of the ground motion, which has a minor contribution to instability (Romeo 2000).

The factor of safety of Janbu s Simplified method is obtained from Eq. 12 (Krahn 2004):

$$
F_{\mathrm{SJ}} \frac{\sum c^{\prime} b \cos \theta \quad N \quad u b \tan \phi^{\prime} \cos \theta}{\sum N \sin \theta \quad \sum k_{\mathrm{h}} W}
$$

where $c^{\prime}$ is effective cohesion, $\mathrm{b}$ is the base length of each slice, $\theta$ is the angle between the base of each slice and the horizontal, $\phi^{\prime}$ is effective angle of friction, $u$ is pore-water pressure, $k_{\mathrm{h}}$ is the horizontal seismic coefficient applied through the centroid of each slide, $W$ is

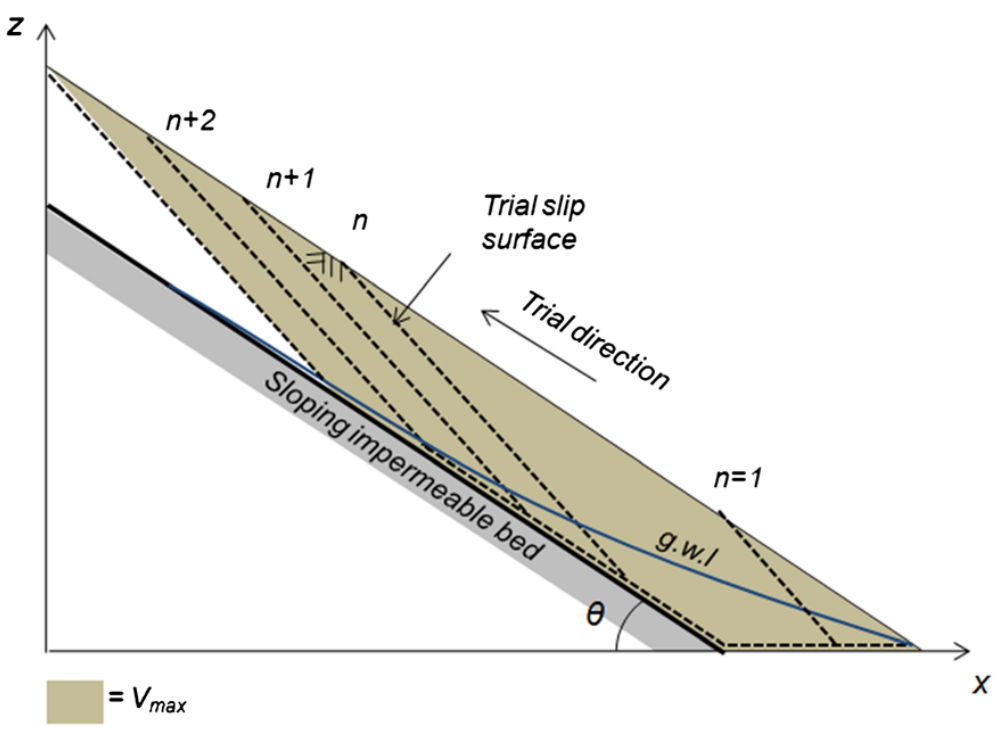

Figure 8 Scheme of slope stability analysis. 
Table 1 Parameters used in stochastic analysis

\begin{tabular}{lllll}
\hline Parameter & Unit & Type & Mean value & Standard deviation \\
\hline Friction angle, $\varphi^{\prime 1,2}$ & $\left({ }^{\circ}\right)$ & Normal & 39.750 & 3.225 \\
Hydraulic conductivity, $k^{1}$ & $(\mathrm{~m} / \mathrm{s})$ & Log-normal & $4.54 ? 10^{-5}$ & $2.81 ? 10^{-5}$ \\
Specific yield, $S^{1}$ & - & Log-normal & 0.331 & 0.291 \\
\hline
\end{tabular}

Data references:

1) Faris and Wang (2014)

2) Wang et al. (2008)

the slice weight and $N$ is slice base normal force, which is defined by Eq. 13 .

$$
N \frac{W \frac{c^{\prime} b \sin \theta u b \sin \theta \tan \phi^{\prime}}{F_{\mathrm{SI}}}}{\cos \theta \frac{\sin \theta \tan \phi^{\prime}}{F_{\mathrm{SI}}}}
$$

The base normal force, $N$ needs to be determined using an iteration process since the factor of safety $\left(F_{\mathrm{SJ}}\right)$ is unknown at the first step of calculation.

The input of pore water pressure $(u)$ to calculate factor of safety is taken from previously discussed groundwater model. The pore water pressure can be simply formulated as Eq. 14.

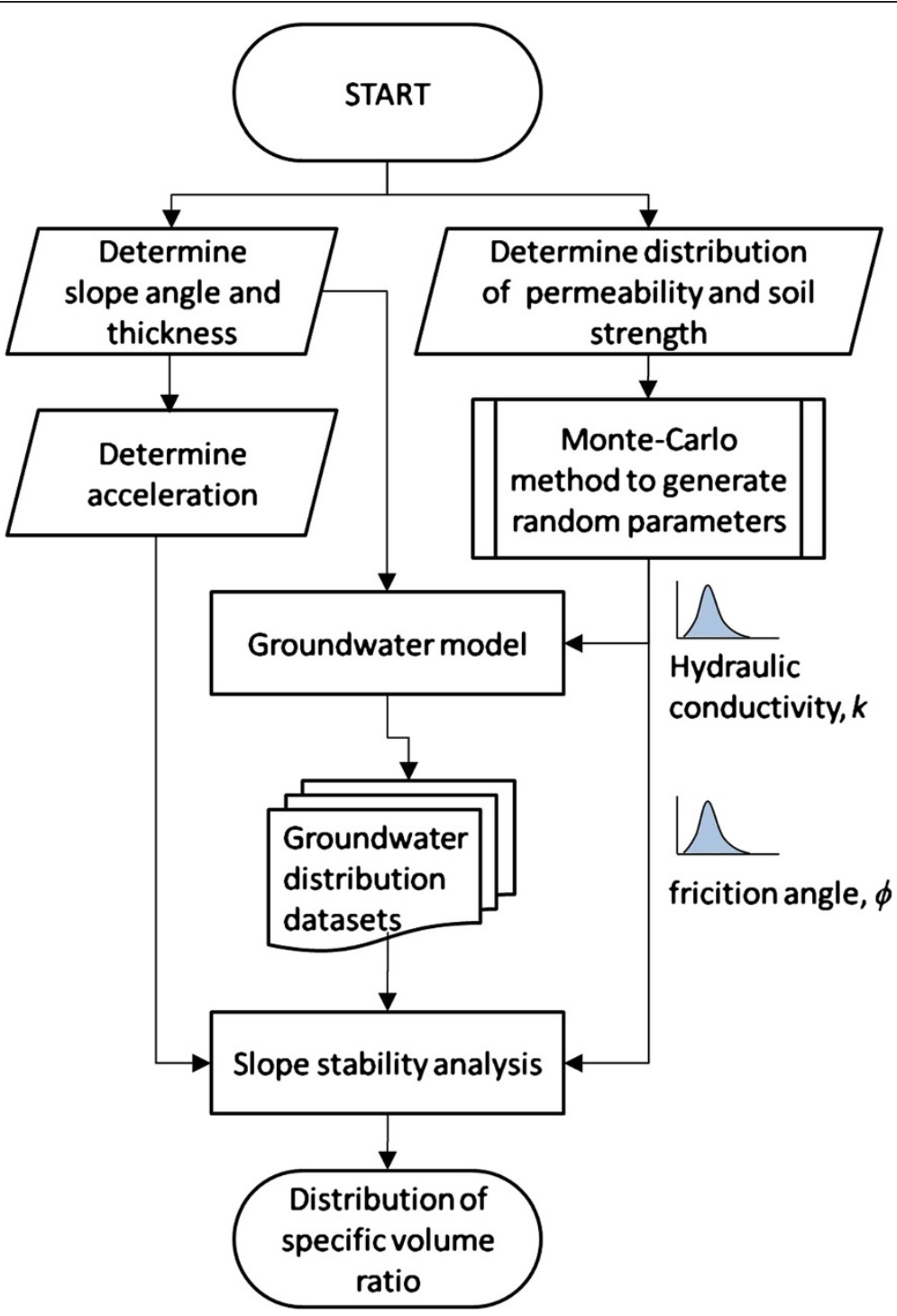

Figure 9 Flowchart of stochastic analysis to determine specific volume ratio. 


$$
u \quad \gamma_{w} h \cos ^{2} \theta
$$

where $h$ is the groundwater height taken from groundwater simulation and $\gamma_{\mathrm{w}}$ is unit weight of water.

\section{Monte-Carlo simulation}

Monte-Carlo simulation was applied as a subroutine in the main program to generate a random variable into both groundwater model and slope stability analysis. It was also applied in the groundwater model to generate the groundwater level data set to be used in the slope stability analysis. From the preliminary simulation, 500 trials for each random variable in Monte-Carlo simulation gave stable result of probability distribution. However, to ensure the reliability of the result, 1000 trials for each random variable were applied in the simulation.

Statistical properties of parameters listed in Table 1 were obtained through the test results, field investigations, and information collected from previous researches. However, it is worthy noting that a certain degree of uncertainty exists in these parameters due to the insufficiency and even erroneousness in the process of data preparation. In this study, friction angle parameter was assumed to be normally distributed, which is the common distribution model for soil strength (Fenton 1996), while hydraulic conductivity was assumed to be log-normally distributed (Fenton 1996; Yang et al. 1996). From the grain size distribution test and the static triaxial test results, Faris and Wang (2014) identified the material of Tandikat landslides as well-graded pumice sand with negligible effective cohesion. Thus, we did not include the effective cohesion in the slope stability analysis.
All the calculations were performed by Visual Basic of Application code of Microsoft Excel ( Microsoft Corporation), which is a powerful and convenient tool for both programming and data analyzing. To enable gradual checking of the groundwater simulation result, the calculations were performed separately (Figure 9). The random variables of hydraulic conductivity were generated by 1000 trials to be used in the groundwater model, which then produced datasets of arrays of groundwater level for each slice in the slope. These datasets were then used in the slope stability analysis and, simultaneously, the random variables of friction angle were generated to be coupled in the analysis. A specific volume ratio was calculated for each random variable of friction angle and groundwater level arrays. 1000 times of calculation were applied to produce the collection of specific volume ratios.

\section{Results and discussion}

Generally, as shown in the Figure 10, the probability distributions of $R_{\mathrm{sv}}$ has unique distribution pattern called bi-modal distribution in which there were two peaks in a series of histogram. This distribution pattern is probably derived from the boundary condition used in this model and the fact that the sliding surface is parallel to the slope surface.

To easily examine the effect of rainfall on the probability of $R_{\mathrm{SV}}$ we tried to compare the result of the analysis of dry conditions and during actual rainfall conditions. The representative results of dry condition are shown in Figure 11 as the histogram of specific volume ratio $\left(R_{\mathrm{sv}}\right)$ incorporated with reversed cumulative curves. A reversed cumulative curve is useful to determine the probability

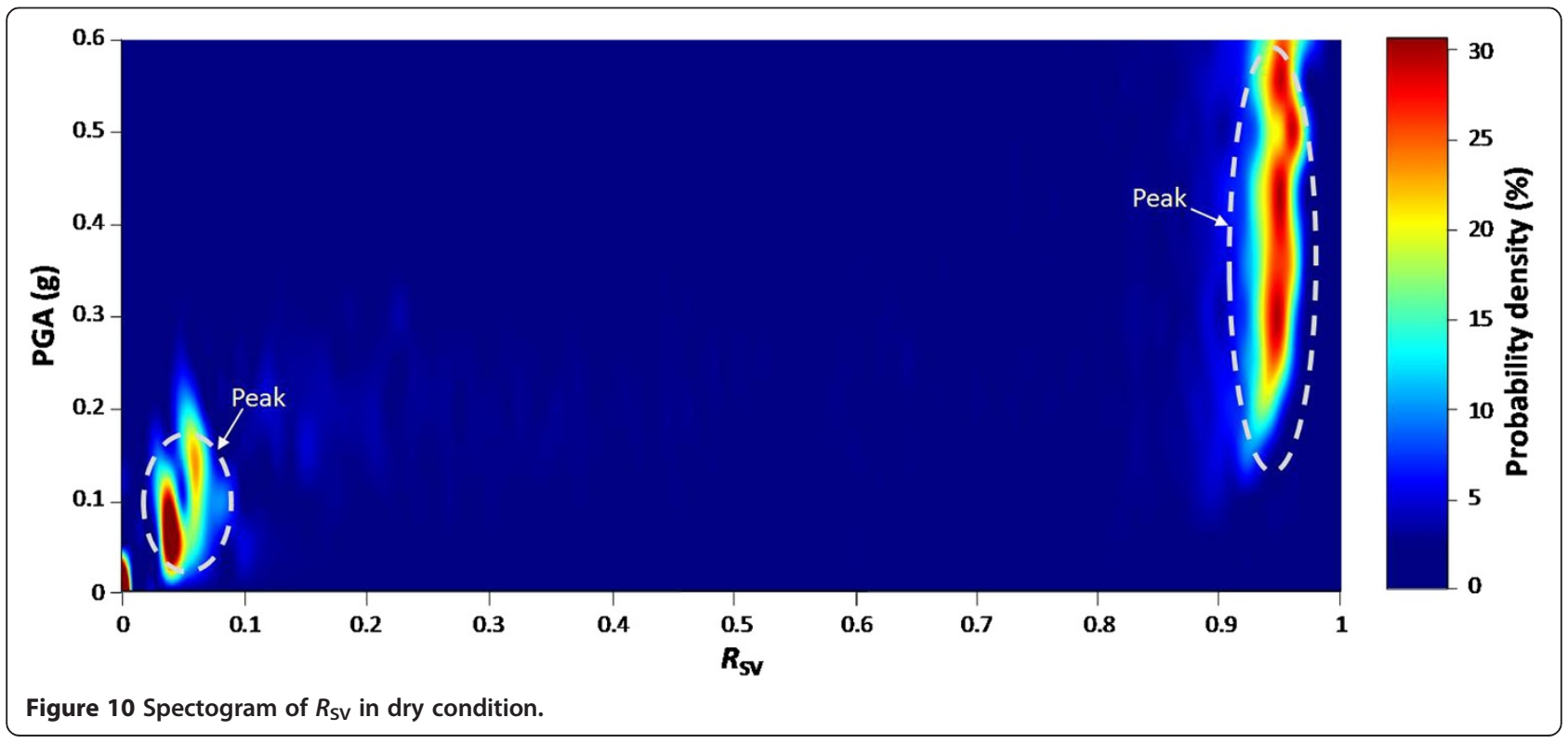



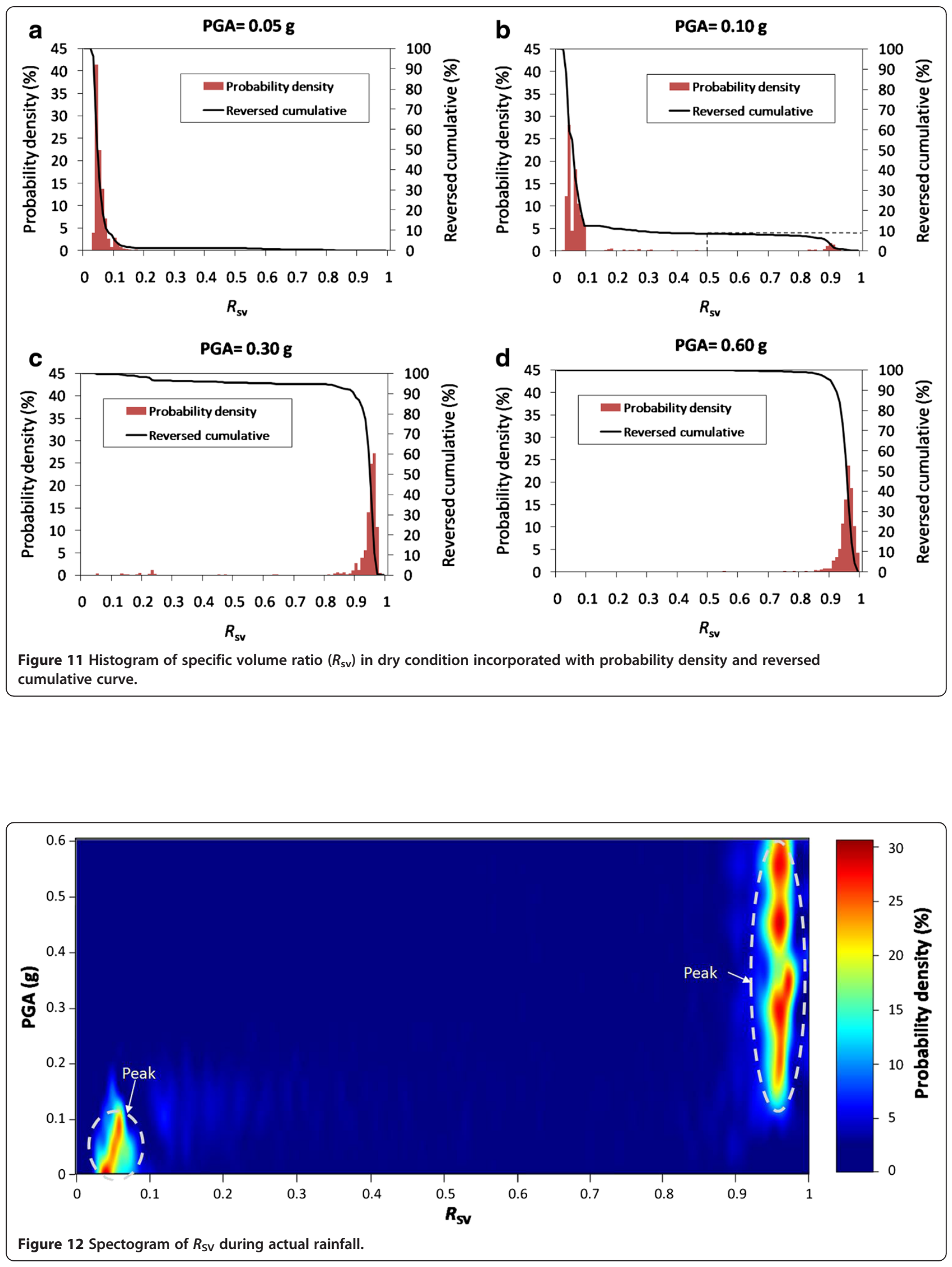


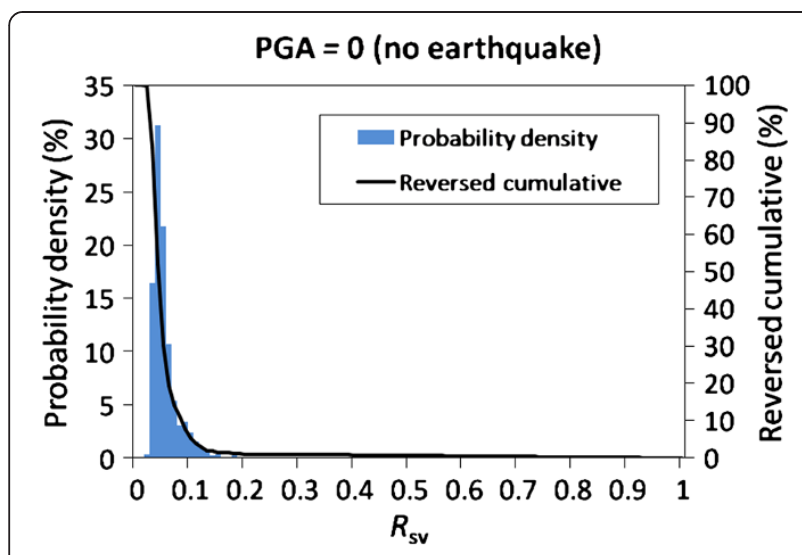

Figure 13 Histogram of specific volume ratio $\left(R_{\text {sv }}\right)$ during actual rainfall without earthquake.

of $R_{\mathrm{sv}}$. As an example, from reversed cumulative curve in Figure 11b, we can determine the probability of specific volume ratio larger than $0.5\left(R_{\mathrm{sv}}>0.5\right)$ is around $10 \%$. Figures $11 \mathrm{a}-\mathrm{d}$ show the probability distribution of $R_{\mathrm{sv}}$ at the peak ground acceleration (PGA) of $0.05 \mathrm{~g}, 0.10 \mathrm{~g}$, $0.30 \mathrm{~g}$ and $0.60 \mathrm{~g}$, respectively. Figure 11a shows that,

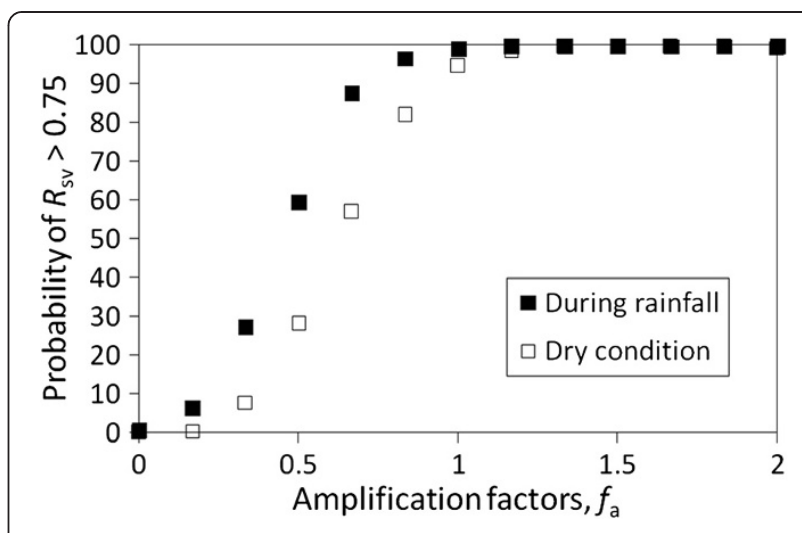

Figure 15 The plot of probability of $R_{\mathrm{sv}}>0.75$ vs amplification factor.

in dry condition, small earthquake with PGA of $0.05 \mathrm{~g}$ would only probably excites minor landslide $\left(R_{\mathrm{sv}}<0.1\right)$, while the Figure $11 \mathrm{~b}$ suggests slight probability $(7.7 \%)$ of major landslide $\left(R_{\mathrm{sv}}>0.75\right)$ when earthquake with PGA of $0.1 \mathrm{~g}$ hit the location. Figure 11c shows that the actual earthquake could probably excited major landslide
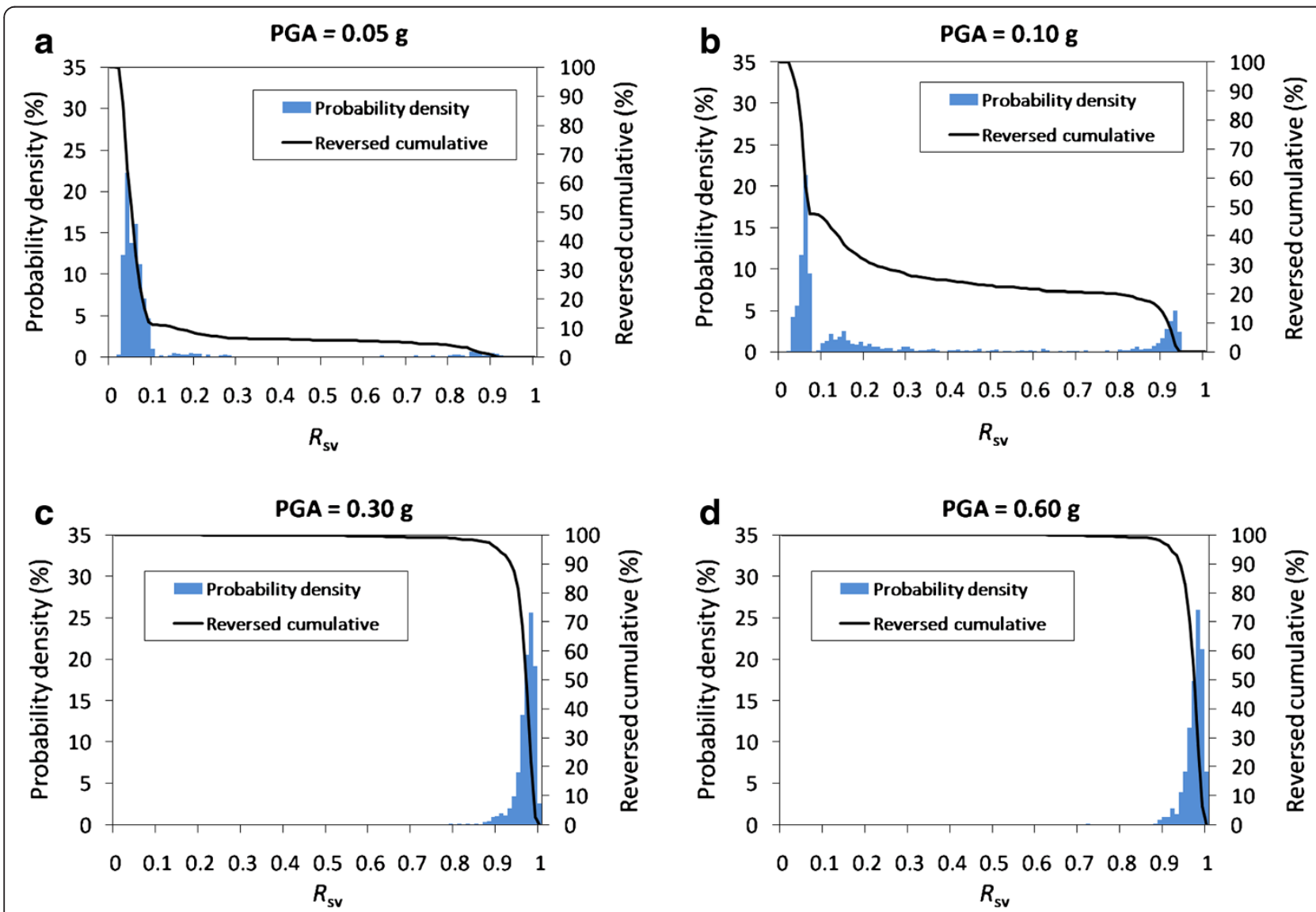

Figure 14 Histogram of specific volume ratio $\left(R_{\text {sv }}\right)$ during actual rainfall incorporated with probability density and reversed cumulative curve. 
even in the dry condition (95\% probability of $R_{\mathrm{sv}}>0.75$ ). Consequently, as suggested in Figure 11d, a greater earthquake only slightly increases the probability of major landslide.

The results of the specific volume analysis during actual rainfall condition are shown in Figure 12, Figure 13 and Figure 14, as the spectrogram of rainfall condition, the histogram of $R_{\mathrm{sv}}$ without any earthquake and the histograms of $R_{\mathrm{sv}}$ with earthquake, respectively. Refer to Figure 12, similar to the dry condition results, the probability distributions of $R_{\mathrm{sv}}$ also shows bi-modal distribution which, again, is probably due to the boundary condition and that the ground water level is parallel to the slope surface in the middle part. Figure 13 shows the probability of distribution of $R_{\mathrm{sv}}$ without any earthquake where $90 \%$ probability of landslide occurred at the toe part of the slope. These landslides were considerably small and only occupied $1 / 10$ of the slope length at the toe part $\left(R_{\mathrm{sv}}=0.1\right)$. Figures $14 \mathrm{a}-\mathrm{d}$ show the probability distribution of $R_{\mathrm{sv}}$ at the peak ground acceleration of $0.05 \mathrm{~g}, 0.10 \mathrm{~g}, 0.30 \mathrm{~g}$ and $0.60 \mathrm{~g}$, respectively.

From Figure $14 \mathrm{a}$, there was around a $5 \%$ probability of major landslide $\left(R_{\mathrm{sv}}>0.75\right)$ when small earthquake with approximated PGA of $0.05 \mathrm{~g}$ hit the area during rainfall. Figure $14 \mathrm{~b}$ shows that there was around a $30 \%$ probability of catastrophic landslide mobilizing more than $75 \%$ of the slope portion $\left(R_{\mathrm{sv}}>0.75\right)$ when the PGA was only $33 \%$ of the actual earthquake $(0.1 \mathrm{~g})$. When compared to Figure 11, it shows that a small earthquake could have a higher probability of generating a major landslide when the earthquake strikes during rainfall instead of during dry conditions. Figure 14c shows that PGA of the actual earthquake (approximately $0.3 \mathrm{~g}$ ) can cause a catastrophic landslide $\left(R_{\mathrm{sv}}>0.75\right)$ with a probability greater than $97 \%$. Whilst, the larger peak ground acceleration did not result in any significant difference from that of actual earthquake (Figure 14d). However Figure 14d shows that, in such situation, half of slope $\left(R_{\mathrm{sv}}>0.5\right)$ has $100 \%$ probability of failure.

To easily comprehend the result, the probability of more than $75 \%$ of the slope portion collapse $\left(R_{\mathrm{sv}}>0.75\right)$ was chosen as the reference. The value of $R_{\mathrm{sv}}>75 \%$ is considered as catastrophic level of landslide hazard. The plot of the probability of $R_{\mathrm{sv}}>0.75$ versus peak ground acceleration is shown in Figure 15 both for dry and during rainfall conditions. It shows that smaller PGA during the actual rainfall could result in a $60 \%$ chance of $R_{\mathrm{sv}}>$ 0.75 , while the dry condition results in a $30 \%$ chance of catastrophic level of landslide hazard. This result cautions the high probability of catastrophic landslide that could happen in the area even if earthquake with PGA as small as approximately 0.15 g occurred during rainfall. However, Figure 15 suggests that a PGA of approximately $0.3 \mathrm{~g}$ is the critical magnitude of ground acceleration that could result in nearly a $100 \%$ probability of catastrophic level of landslide hazard in the area.

\section{Conclusions}

The probability distributions of specific volume ratio of shallow landslide has unique distribution pattern called bi-modal distribution in which there were two peaks in a histogram. This distribution is derived as a result of the boundary conditions used in this model and also because the sliding surface is parallel to the ground water level in the middle part of the slope.

The stochastic analysis of the Tandikat landslide confirms that smaller earthquakes could possibly trigger catastrophic landslides during rainfall. Smaller peak ground acceleration of approximately $0.15 \mathrm{~g}$ could result in more than a $60 \%$ chance of $R_{\mathrm{sv}}>0.75$, while the analysis of dry condition yields a $30 \%$ chance of the occurrence of a catastrophic level of landslide hazard. This suggests that rainfall condition increases the probability of catastrophic landslide.

Peak ground acceleration larger than the actual earthquake have negligible effect on the probability of $R_{\mathrm{sv}}>0.75$ in a particular event. The results suggest that peak ground acceleration of approximately $0.3 \mathrm{~g}$ is considered as the critical magnitude of ground acceleration that would result in a nearly $100 \%$ probability of catastrophic level of landslide hazard in the area.

\section{Competing interests}

The authors declare that they have no competing interests.

\section{Authors contributions}

FF carried out numerical modelling and manuscript preparation; FW provided suggestions and advices to the study and checked the manuscript; all authors read and approved the final manuscript.

Received: 22 July 2014 Accepted: 5 December 2014

Published online: 24 December 2014

\section{References}

Agus SM, Liao HJ (2009) Analysis of rainfall-induced infinite slope failure during typhoon using a hydrological geotechnical model. Environ Geol 56:1145 1159

Aydan? (2009) A reconnaisance report on the Pariaman-Padang earthquake of September 30, 2009. Japan Society of Civil Engineers, Japan, 36 pp

Bansal RK (2013) Modelling of groundwater flow over sloping beds in response to constant recharge and stream of varying water level. International Journal of Mathematical Modelling \& Computations 4(3):189 200

Bansal RK, Das SK (2010) An analytical study of water table fluctuations in unconfined aquifers due to varying bed slopes and spatial location of the recharge basin. J Hydrol Eng 15(11):909 917

Chang KT, Chiang SH, Hsu ML (2007) Modeling typhoon- and earthquakeinduced landslides in a mountainous watershed using logistic regression. Geomorphology 89:335 347

Chowdhury RN, Xu DW (1994) Slope system reliability with general slip surface. Soils and foundations 34(3):99 105

Duncan JM, Wright SG (2005) Soil Strength and Slope Stability. John Wiley \& Sons, Inc, New Jersey

Eckis R (1934) South coastal-basin investigation geology and ground-water storage capacity of valley fill. California Department of Public Works, Water Resources Division, Bulletin 45:279

Faris F, Wang FW (2014) Investigation of the initiation mechanism of an earthquake- induced landslide during rainfall: A case study of the Tandikat 
landslide. Geoenvironmental Disaster, West Sumatra, Indonesia, 1(4). doi:10.1186/s40677-014-0004-3

Fenton GA (1996) Probabilistic method in geotechnical engineering. Workshop note of ASCE GeoLogan 97 Conference. ASCE Geotechnical Safety and Reliability Committee, Logan, Utah, p 96

Griffiths DV, Fenton GA, Tveten DE (2002) Probabilistic geotechnical analysis: How difficult does it need to be? In: Klapperich RPH, Schweiger H (eds) Proceedings of the International Conference on Probabilistics in Geotechnics: Technical and Economic Risk. United Engineering Foundation, New York, Graz, Austria

Iverson RM (2000) Landslide triggering by rain infiltration. Water Resources Res 36(7):1897 1910

Krahn J (2004) Slope stability modeling with SLOPE/W, An Engineering Methodology. GEO-SLOPE /W International, Ltd, Calgary, Alberta, Canada, $396 \mathrm{pp}$

Odong J (2007) Evaluation of empirical formulae for determination of hydraulic conductivity based on grain-size analysis. J Am Sci 3:54 60

Petersen M, Harmsen S, Mueller C, Haller K, Dewey J, Luco N, Crone A, Lidke D, Rukstales K (2007) Documentation for the Southeast Asia Seismic Hazard Maps. Administrative Report, U.S. Geological Survey, 67 pp

Refice A, Capolongo D (2002) Probabilistic modeling of uncertainties in earthquake-induced landslide hazard assessment. Computer \& Geoscience 28:735 749

Robson SG (1993) Techniques for estimating specific yield and specific retention from grain-size data and geophysical logs from clastic bedrock aquifers. In: Water-resources investigation report 93-4198. U.S. Geological Survey, Denver, Colorado, $\mathrm{p} 19$

Romeo R (2000) Analysis of rainfall-triggered infinite slope failure during typhoon using a hydrological geotechnical model. Eng Geol 58(2000):337 351

Sassa K (2005) Landslide disasters triggered by the 2004 Mid-Niigata Prefecture earthquake in Japan. Landslides 2:135 142

Shou KJ, Wang CF (2003) Analysis of the Chiufengershan landslide triggered by the 1999 Chi-Chi earthquake in Taiwan. Eng Geol 68:237 250

Sipayung SB, Lely QA, Bambang DD, Sutikno (2007) The analysis of rainfall pattern in Indonesia based on global circulation model (GCM) output. Jurnal Sains Dirgantara 4(2):145 154, in Indonesian

Sloan PG, Moore ID (1984) Modeling subsurface stormflow on steeply sloping forested watersheds. Water Resources Res 20:1815 1822

Steenhuis TS, Parlange JY, Sanford WE, HeiligA SF, Walter MF (1999) Can we distinguish Richards and Boussinesq s equations for hillslopes?: The Coweeta experiment revisited. Water Resources Res 35(2):589 593

Uzuoka R, Sento N, Kazama M, Unno T (2005) Landslides during the earthquakes on May 26 and July 26, 2003 in Miyagi, Japan. Soils and Foundations 45(4):149 163

Wang H, Wang G, Wang FW, Sassa K, Chen Y (2008) Probabilistic modeling of seismically triggered landslides using Monte Carlo simulations. Landslides 5:387 395

Wu P, Hara M, Hamada Jl, Yamanaka MD, Kimura F (2009) Why a large amount of rain falls over the sea in the vicinity of western Sumatra Island during nighttime. J Appl Meteorol Clim 48:1345 1361

Yang J, Zhang R, Wu J, Allen MB (1996) Stochastic analysis of adsorbing solute transport in two-dimensional unsaturated soil. Water Resource Res $32: 2747 \quad 2756$

doi:10.1186/s40677-014-0012-3

Cite this article as: Faris and Wang: Stochastic analysis of rainfall effect on earthquake induced shallow landslide of Tandikat, West Sumatra, Indonesia. Geoenvironmental Disasters 2014 1:12.

\section{Submit your manuscript to a SpringerOpen ${ }^{\odot}$ journal and bene $\otimes t$ from:}

- Convenient online submission

- Rigorous peer review

- Immediate publication on acceptance

- Open access: articles freely available online

- High visibility within the 囚eld

- Retaining the copyright to your article

Submit your next manuscript at $\gg$ springeropen.com 